\title{
DE L'«ECONOMIA INFORMAL» A «FORMES DE TREBALL»: MODELS I TENDENCIES TRANSNACIONALS *
}

\author{
R. E. Pahl \\ (Universitat de Canterbury)
}

En aquest article Pabl aposta per una investigació transnacional i comparativa de l'economia informal, que decididament prefereix anomenar formes de treball informal, per ser aquest un concepte més precis i capaç d'englobar des del treball dit negre fins a les feines d'autoabastament.

Agatant com exemple l'acció de planxar, Pabl fa un recorregut per les. diferents formes de treball que tal acció pot significar $i$ que van des del treball pagat per peça a fins al treball voluntari, tot desafiant les formulacions simplistes de l'economia informal.

L'article es clou amb el rebuig de les tesis economicistes $i$ amb un ad. vertiment als sociòlegs perquè encarin els fenòmens que comporten les di. verses formes de treball informal, suggerint que la sociologia del trebalt. pot aportar molta llum sobre els aspectes menys clars si se centra en les causes $i$ deixa de documentar les conseqüiencies del fenomen.

En l'última dècada bi ha hagut un notable creixement de l'interès en allò que vagament s'anomena economia informal. Conferències internacionals celebtades a Alemanya, Itàlia, els Estats Units i a altres llocs han reunit especialistes de diverses disciplines que pensen que tenen coses en comúper discutir. De la mateixa manera, governs i organitzacions intergoverna-

* De propera aparició a Divisions in Western Capitalism and State Socidism,. Georg Alten, 1989.

1. Per exemple, Consiglio Italiano per le Scienze Sociale: The Informal Economy, 
mentals han encarregat, $i$ en molts casos han publicat, analisis que pretenen aplegar una comprensió cumulativa internacional d'un fenomen que ha motivat un interès públic considerable. ${ }^{2}$ Comentaris sobre l'economia submergida, l'economia amagada, l'economia a l'ombra o economies amb etiquetes similars es combinen amb intents més acadèmics per avaluar l'adequació metodològica de les temptatives per classificar la magnitud de l'abast, l'envergadura $i$ la incidència del fenomen. ${ }^{3}$

Les investigacions sobre l'economia informal van des de detallats estudis de casos particulars de l'activitat econòmica informal a Bogotà, Budapest o Bari, a anàlisis macroeconòmiques que pretenen explicar l'escala del fenomen als Estats Units, Gran Bretanya o Holanda (Bromley i Gerry, 1979; Galasi i Sziracki, 1985; Renooy, 1984; Inchiesta, 1986). A vegades aquests estudis estan clarament orientats a problemes polítics o de politiques públiques $i$ el fenomen investigat es pot entendre com un problema a reduir mitjançant la gestió, com una solució a adoptar o com un tret ambigu d'una societat que, potser, setia millor deixar córrer (OCDE, 1986b; Pahl, 1987). D'altres vegades, el fenomen es tracta històricament i el seu context agafa un caire prominent (Ditton, 1977; Pahl, 1984). Això no obstant, generalment, els estudis es presenten ahistòricament i la investigació transnacional rigorosa gairebé no existeix. Això és comprensible ja que el fenomen comporta un concepte de calaix de sastre que inevitablement ha eludit una defnició precisa $i$ universalment acceptable. La investigació transnacional és força arriscada perquè tracta amb uns fenòmens que poden ser definits bastant fàcilment: sense acord sobre el que s'estigui comparant, aquells qui estan compromesos amb un exercici com aquest hauxien de ser cautelosos. L'objecte cientific no ha de ser tan sols definit acuradament sinó que també s'ha de clarificar la naturalesa de la investigació comparativa. Kohn (en un estudi en premsa) ha suggetit útilment que hi ha quatre tipus d'investigació transnacional. En el primer el país és l'objecte d'estudi; en el segon, el país és el context d'estudi, en el tercer pot ser la unitat d'analisi $i$, finalment, els estudis poden ser de caràcter transnacional.

Social Conflicts and the Future of Industrial Society. Conferència Internacional a Villa Tuscalona, Frascati (Roma), novembre 1982, i la Conferència les ponències de la qual aparegueren en Gaettnet i Wenig (1985). Això no obstant, 1986 ha estat el woillor: se celebraren conferències a Messina (Sicilia) el maig, a Bielefield (RFA) el setembre i a Harper's Ferry, West Virginia, a l'octubre. I segut que en podríem afegir més.

2. Veure especialment OCDE 1986b: 66.79 i les referències que se citen allà. Més recentment la Comissió Eutopea de Brusselles (DGV) ha emprès una investigació sobre el treball negre en els seus Estats-membres, que es preveia publicar el 1989.

3. Mattera (1985) ha fet un informe divulgatiu, ben investigat $i$ viu. Per a critiques ben informades i escèptiques sobte el treball d'economistes, especialment als Estat Units i a Gran Bretanya, vegeu Smith (1986) i Thomas (1988). 
La major part de la investigació comparativa se centra en el tipus segon, el país com a context d'estudi. De tota maneta, estudis sobre l'economia informal poden orientar-se a paissos concrets, com Itàlia o Hongria (Mingione, 1988; Sik, 1988), perquè tenen punts interessants. Per exemple, les interrelacions entre treball formal $\mathrm{i}$ informal en aquests dos contextos oposats ens poden dir molt sobre la naturalesa específica d'aquestes dues societats, «el que distingeix la investigació que tracta el país con a unitat d'anàlisi és la seva preocupació essencial per comprendre com les institucions i els processos socials es relacionen sistemàticament amb variacions en les cav racterístiques nacionals» (Kohn, en premsa).

Malgrat aquestes alliçonadores advertències, actualment hi ha un acord generalitzat, com a mínim a Europa, sobre el fet que l'anàlisi del treball i de l'ocupació en les societats capitalistes i les de socialisme d'Estat ha estat massa limitada en el passat. Formes informals i nous models de treball dins i fora de l'ocupació han de ser explorats per revelar elements de canvi social que els enfocaments tradicionals han ignorat. Les tradicionals i convencionals divisions del treball en la societat s'estan renegociant: ocupació informal i treball al marge de l'ocupació són ingredients essencials en aquest procés que necessita ser entès (Gorz, 1982; Gershuny, 1983; Pahl, 1984, capítoI 12). La confusió entre treball i ocupació en l'estil dels antiquats textos de Sociologia del treball es veu ara com un arcaisme curiós i l'enigma és per què els sociòlegs mantingueten durant tant de temps concepcions tan restringides del treball.

Aquí no és possible proveir una documentació completa sobre l'extensa i creixent literatura que ha sortit en els darrers anys a Europa $i$ als Estats Units, especialment des de l'innovador treball de Ferman, Brendt i Selo (1978). Aixf i tot, intentaré d'oferir indicadors analítics per aclarir les confusions conceptuals i de definició. Després acabaré suggetint un mitjà per a superar taxonomies formals de les activitats de l'economia informal $i$ bus. car una aproximació més basada en la sociologia.

\section{APROXIMACIONS A L'ECONOMIA INFORMAL}

Per clarificar el terreny s'han d'assenyalar algunes qüestions generals. Primer, la noció d'una economia informal en les societats més desenvolupades implica la recíproca existència d'una economia formal, ja que les normes, les regulacions i els procediments que regeixen l'economia formal creen les condicions per a l'evasió o la trampa; en canviar constantment unes normes tan formals - -ja que l'Estat canvia, entre modes $i$ estils de regt. 
lació i desregulació-, l'economia informal creix o disminueix. Si els Estats $i$ les organitzacions internacionals volen realment imposar els seus sistemes de regulació, o bé si desitgen mesurar millor la suposada pèrdua d'impostos, llavors es preocuparan de pagar economistes i d'altres per a recopilar estadístiques comparatives que demostrin la magnitud de l'activitat econòmica, la qual creuen que hautia d'estar en la Comptabilitat Nacional, però que els costa de percebre. Un informe publicat per l'OCDE el 1986 conclogué que hi podria haver entre «el 2 i el 4 per cent d'ocupació submergida (en termes de treball) de l'input total de treball mesurat en hores de treball en els paisos més industrialitzats, encara que aquest percentatge podria arribar al 8 per cent» (OCDE, 1986b: 69). Evidentment, afirmacions comparatives tan abstractes (la investigació transnacional comparativa de Kohn, per exemple) generalitzen molt $i$ pot ser que no tinguin un gran valor acadèmic o pràctic. No obstant això, enfocar les formes de regulació i desregulació pot oferir, en realitat, una base útil per a la investigació transnacional, tal com pretenc de provar més endavant.

Recopilar indicadors de l'economia informal suposa que, d'alguna manera, la recíproca economia formal ens ofereix una base fixa. Ara bé, si agafem les economies de, per exemple, Kenya, Afganistan, Hongria i Dinamarca, és evident que són més destacables les diferències entre les societats de socialisme d'Estat $i$ les liberaldemocràtiques, o bé entre les diferents formes de societats postcolonials en desenvolupament, que no pas la simple dicotomia formal-informal. Les estadístiques que indiquen ordres de magnitud semblants poden ocultar més que no pas revelar. Els comentaris de Stefan Nowak són aquí pertinents: «Com podem saber que estem estudiant "Ia mateixa cosa" en contextos diferents? ¿Com podem saber que les nostres observacions $i$ conclusions no es refereixen, en realitat, a "coses força diferents" que incloem en la mateixa categoria conceptual sense cap justificació? $O$ bé si semblen diferents, ¿són realment diferents respecte a la mateixa variable (entesa qualitativament o quantitativament), 0 és que la nostra conclusió sobre la diferència entre elles no té significat cientific?» (Nowak 1976: 105). Regulació i destegulació poden respondre processos globals però són, segurament, específiques del context fins a un cert grau d'importància. Mel Kohn resumeix la qüestió així: «No hi ha cap manera d'estar segur si les aparents diferències entre paisos són reals o "artifactuals"》 (Kohn, en premsa).

En tercer lloc, la idea que hi ha múltiples economies en qualsevol formació social s'ha d'examinar acuradament. Sota el capitalisme tnodern i occidental la moneda, el sistema bancari i la concepció de les relacions de mercat són comunes: la base d'una economia separada costa de distingir. Un 
intent de diferenciar quatre subeconomies en el Regne Unit fou plantejat ja per Davis el 1972. La seva descripció no ha estat útilment superada.

«La subeconomia del mercat està regida per Ileis de comerç, d'ocupació, de relacions laborals, etc, $\mathrm{i}$ inciou totes les transaccions de serveis $\mathrm{i}$ mercaderies. L'economia redistributiva està regida per lleis fiscals i d'assistència social i despesa pública. L'economia donnèstica està regida finalment per la norma familiar, però de forma més immediata per costums i expectatives, més o menys idiosincràtiques, relatives a les relacions entre els membres de la familia; inclou totes les activitats productives que no estan intervingudes per un mercat (fer i millorar, processar aliments, etc.), així com la gran part de les activitats del consumidor. L'economia de l'obsequi es regeix per les lleis de reciprocitat, $i$ inclou totes aquelles transaccions que anomenem fer un regal, obsequiar, etc.» (Davis, 1972: 408).

Davis aclareix que no pretén fer una lista exhaustiva. Altres han contrastat el sistema de planificació estatal de les societats socialistes amb els parallels, sovint informals, sistemes de mercat de la mateixa societat. ${ }^{4} \mathrm{~Pa}$ radoxalment, per tant, la noció d'esferes econòmiques separades o d'«economies» pot ser més relevant en societats de socialisme d'Estat, cosa que discutiré després amb més detall.

En quart lloc, hi ha una claredat enganyosa quan es fa referència a tot aquell treball que no és part de l'ocupació formal com l'economia informal. La utilització del terme «economia informal» seria apropiat, en primer lloc, si l'activitat informal es referís a una esfera veritablement separada i independent d'una altra economia. Això es podria donar en una econonnia centralment planificada, on l'activitat econòmica que opera d'acord amb els principis del mercat existeix juntament o parallelament a l'economia «oficial» formal. Aquí l'èmfasi està en la diferent forma 0 tipus d'economia. Una segona acepció on es podria emprar el terme seria la que es teferís a totes aquelles activitats econòmiques que són ombres de l'economia formal. Així, algun treballador autònom pot declarar només una part de les seves activitats al fisc per constar com a part de l'economia formal. Si aquella persona realitza altres activitats o té una altra feina, però no declara els beneficis o ingressos que li generen, llavors això es pot qualificar de treball submergit en l'economia informal. Així, cada tipus d'activitat econò-

4. Hi ha indicis per a dit que Gorbatxov dóna suport a aquesta distinció entre el sistema públic estatal i el sistema privat de mexcat (si és que no li'n donen tots els seus collegues). 
mica formal tindrà la seva rèplica informal. El primer ús del terme econo" mia informal emfasitza el substantiu, el segon l'adjectiu.

A part d'aquestes dues utilitzacions diferents, l'expressió pot incloure diverses formes de treball que no són part ni d'una economia parallela ni d'una ombra de l'economia formal de mercat. S'entenen millor com a formes de treball específiques i seria confús i conceptualment poc sòlid ajuntar totes aquestes diverses formes de treball. Sens dubte setia augmentar l'er* ror referit-se al mencionat conjunt de formes diverses de treball com eco. nomia separada. Aquells que intentin fer-ho haurien d'ajuntar una gamma d'activitats que inclogués des de la delinqüència ocupacional, el treball domèstic fins als quasi-bobbies com la jardineria. Els treballadors empobrits de les ciutats més pobres del món, de la mateixa manera que els treballadots opulents de les ciutats més riques, poden treballar amb les eines pròpies en el seu propi temps per produit béns i serveis per a la seva llar. Evidentment, algunes formes de treball són culturalment específques: el bricolatge, per exemple, pot tenir més èxit a Gran Bretanya que al Japó. Una de les conseqüències de resumir una gamma d'activitats sota el títol general de treball informal és que formes de treball força diferents poden afegir-se a ordres de magnitud generals aparentment semblants com podria passar entre societats diferents. Perquè tals comparacions tinguin sentit és crucial que el concepte general sigui desagregat en els seus elements constituents. Només quan formes de trebail específiques es distingeixen conceptualment, és quan l'anàlisi comparativa és fiable. Reprendré, però, aquest tema més endavant. (Vegeu també PahI, 1984, capítol 5.)

Per donar alguna idea de la gamma de contextos en què s'empren els termes treball informal i economia informal es poden mencionar diverses qüestions $\mathrm{i}$ diversos debats. Ambdós tenen una literatura pròpia i m'hi refereixo només amb l'objectiu d'illustrar i sense pretendre ser exhaustiu. Alguns autors poden referir-se a les mateixes activitats com a part d'una economia informal, d'altres a un sector informal i d'altres simplement al treball informal, travail au noir, o schwarzarbeit, entre altres termes.

a) Es fa referència a una gamma d'activitats que poden anomenar-se estratègies de supervivència pels pobres de les barriades de les ciutats del Tercer Món o del sud d'Itàlia (Mingione, 1983). El debat se centra en la quiuestió de si aquesta és una opció o bé és el resultat d'una elecció entre possibilitats alternatives de guanyar-se la vida.

b) Nous i alternatius modes de provisió de serveis en la societat industrial avançada estimulen l'extensió del treball al marge de l'ocupació (Skolka, 1975 i Gershuny, 1979). Autoprovisió o bricolatge, utilitzant nova tecnologia per entretenir-se i produir serveis privadament que anteriorment només s'oferien públicament, són aspectes d'un debat que, per implicació, 
poden aplicar-se a totes les societats industrials. Les que tinguin els nivells més alts de producció material es pot esperar que mostrin la tendència més pronunciada (Gershuny, 1983; Pah1, 1984). La dita nova economia de serveis està molt inclinada cap a la provisió dels serveis propis. El debat se centra en el grau en què la provisió informal de serveís pot incrementar-se.

c) El treball al marge de l'ocupació, també anomenat «economia informal», ha estat proclamat com la font d'un nou estil de vida alliberat en el qual la gent s'emancipa de les càrregues de les relacions opressores del capitalisme o de les constriccions dels sistemes feixucs i burocràtics de distribució. El treball en el "terreny de la necessitat» es redueix mentre el treball en el «terreny de la llibertat» augmenta, emprant la terminologia de Marx. Actualment, això es pot observar en la nova emergència de formes de vida alternatives. ${ }^{5}$ La discussió aquí se centra en fins a quin punt aquestes formes són senyals significatius d'esdeveniments futurs o bé epifenòmens insignificants.

d) Hi ha un debat sobre si el treball social i assistencial al marge de l'Estat del benestar formal pot ser una manera alternativa d'oferir serveis socials $i$ sistemes de suport. Aquest tipus de treball s'hauria de distingir de les xarxes assistencials dels pobres, i és més aviat un producte de la prosperitat material, d'una més gran disponibilitat de temps i d'habilitats i d'una ideologia altruista de preocupació i assistència. Grups d'ajuda mútua i for. mes d'organització cooperativa variades destaquen molt en aquesta perspectiva (Heinze i Olk, 1982). Els seus crítics ho entenen com a una possible base per a una major explotació de la dona (Ungerson, 1987; Parker, 1988).

e) Una altra àrea polèmica fa referèncía al nivell en què l'economia informal (o sector) pot ser una font de dinamisme tant en societats capitalistes com socialistes. El postfordisme a Occident es relaciona amb una major «flexibilitat» que inclou subcontractació, treball a domicili i el creixement d'una força de treball temporal o a temps parcial. ${ }^{6} \mathrm{EI}$ debat se centra ara en si l'anomenat model de subcontractació «Emilià», del qual tant s'ha parlat, es pot aplicat en altres contextos (Sabel, 1982). Allò que pot emancipar i crear riquesa sota un conjunt de relacions socials pot ser opressiu i empo-

5. Vegeu Gorz (1982) op. cit., James Robertson, Future Work, Gower, Aldershot, 1985, i la xatxa internacional organitzada per James Robertson i Alison Pritchard de l'Old Bakehouse, Cholsey, Near Wallingford, Oxfordshire, OX $109 \mathrm{NV}$. Hi ha opuscies i fulls informatius. Els lligams semblen ser més forts amb altres a Canadà, els EUA, la RFA, Escandinàvia, Gran Bretanya i Holanda -vegeu les referències de Robertson.

6. La literatura sobre «fiexibilitat» $\mathrm{i}$ «reestructuraciós és àmplia $\mathrm{i}$, en gran part, efímera. Una introducció útil és Flexibility in the Labour Market: the Current Debate, OCDE, París, 1986. Vegeu també C. Sabel i M. Piore, The Second Industrial Divide, Basic Books, 1985, i el ja clàssic informe d'A. Bagnasco Tre Italie: la Problematico. Territoriale Dello Svilupo Italiano, Bologna, Il Molino, 1977. 
bridor sota un altre. És difícil marcar la divisòria entre l'evasió d'impostos - la utilització de mà d'obra batata (desafiant la legislació de protecció laboral) i ser un empresari creador de riquesa que estableixi petits negocis ajudant el capitalisme a ser realment dinàmic. De la mateixa manera, com ha demostrat Stark en referència a Hongria, «... també és difícil marcar la distinció entre un getent Ileial del sistema econòmic de l'Estat i un pirata minant el sistema a través de la subcontractació informal internas (Stark, 1986).

El darrer exemple demostra molt bé l'ambigüitat i la contradicció inherent en el terme «economia informal». No seria difícil establir algunes dicotomies paradoxals. Tal com hem vist, l'economia informal pot ser presentada en termes d'aprovació (vinculada a nocions d'emancipació, Jlibertat, autoexpressió, treball no alienat, més gemeinsbaftlich, i a activitats expressives). Però, de la mateixa manera, l'economia informal pot tenir connotacions d'illegalitat, explotació, opressió i coerció instrumental. Pot ser un simbol de dinamisme $\mathrm{i}$ de declivi, d'estructures i comportaments ptogressius i regressius, un indicador d'esperança i de desesperació. Així la modernització, d'una banda, pot entendre's com una manera de reduir els procediments $i$ les pràctiques personalitzades $i$ informals «menys eficients» per expandir els sistemes bancaris i de mercat centralitzats. Una trajectòria alternativa de canvi social veu l'economia o el sector informal com si es basés en un estil empresarial que serà important per trencar motlles, trencar estructures polítiques i d'organització massa tígides, indicant, així, el camí cap a un futur més eficient (Piote i Sabel, 1984). Una posició intermèdia, adoptada tàcitament pels governs italià $i$ irlandès, veutia la tensió creativa entre pràctiques informals i formals com a ingredients essencials d'un «bon» sistema econòmic: el problema és bàsicament aconseguir I'equilibri. No obstant això, fixar-se només en els nivells de regulació i desregulació pot produir estadistiques comparatives interessants per a polítics i administradors, però pot tenir poc sentit sociològic.

En un article sobre les societats capitalistes occidentals els autors mantenen que «la informalitat sembla que creix, com a mínim en alguns sectors» (Portes i Sassen-Koob, 1987: 47) (aquesta observació tan poc excepcional ha estat, des de fa ja algun temps, part del saber convencional entre els que treballen en aquest camp, vegeu Barthelemy, 1982; Heinze i Olk, 1982; Gaertnet i Wenig (eds.), 1985; Mingione, 1983, 1985; OCDE, 1986b; O'Higgins, 1980, 1985; Pahl, 1984), i, per sostenir aquesta afirmació, els autors presenten dades del Bureau of Statistics dels Estats Units que demostren que un elevat percentatge dels empleats nord-americans treballen en petites empreses (Very Small Establisbments.VSEs) és a dir, donen ocupació a menys de 10 treballadors. Els autors demostren que les pèr- 
dues substancials de llocs de treball en la ciutat de Nova York entre 1970 i 1980 han estat parcialment compensades per un creixement ràpid de les VSEs, especialment en el diversificat sector dels serveis privats als consumidors. Aquesta explicació no té res d'excepcional. Això no obstant, sorprenentment els autors procedeixen a interpretar el creixement d'aquestes petites empreses com un substitut al creixement de l'economia informal.

Fent això no aconsegueixen distingir entre diferents classes de petites empreses $\mathrm{i}$ formes específiques de relacions socials. Potser, d'una banda, les empreses es poden basar en la nova alta tecnologia, en la qual un grup reduit de professionals genera un alt component de valor afegit al seu pro. ducte o servei, assegurant així que tots s'enriqueixin; i d'una altra banda podrien ser tallers clandestins, on el propietari pot fer grans beneficis mentre els seus treballadors teben sous miserables. En els dos casos la forma de treball pot ser més o menys formal. En un extrem, el primer tipus de VSEs podria declarar totalment tots els seus negocis a Hisenda, i el segon podria legalment donar feina a dones a temps parcial, per exemple, respecte a les quals l'emptesari tindria ben poques obligacions. En l'altre extrem, el primer tipus d'empresari podria fer beneficis elevats però només un petit percentatge es declararien a Hisenda, mentre que el propietari del taller clandestí podria donar feina a gent per Ilargues jornades amb sous baixos i no complit amb les seves obligacions d'empresari pel que fa a salubritat, seguretat en el treball, dret a vacances, etc., i no declarar tots els treballadors a qui donaria ocupació.

En segon lloc, els autors afirmen que «treballadors acomiadats augmenten l'oferta de treball disponible per a activitats informals per escapar-se de Ia desocupació de llarga durada $i$ incrementar els seus miserables ingressos» (Portes i Sassen-Koob, 1987: 55). No obstant això, ara hi ha una literatura considerable que demostra inequívocament que els desocupats en molts països europeus són els que són menys proclius a estar vinculats al treball informal (Foudi et al., 1982; EIU, 1982; OCDE, 1986b; Pahl, 1987).

Finalment, en confondre VSEs amb la informalitat i l'economia informal, els autors no tenen en compte totes les altres formes de treball informal que poden tendir a augmentar en la societat industrial (Gershuny, 1983; Inchiesta, 1986; Pahl, 1984; Redclift i Mingione, 1985; Skolka, 1976).

No hi ha dubte que els autors tenen taó en considerar les implicacions socials de la regulació i la desregulació en contextos donats $i$, per tant, el paper del govern en determinar els nivells de l'ocupació informal. També destaquen que «la correspondència recíprocament avantatjosa entre les necessitats dels treballadors $i$ les estratègies de les empreses no es podria produir en un ambient polític hostil» (Portes i Sassen-Koob, 1987: 56). Desafortunadament, això és la conclusió, més que no pas el punt de partida de 
«Papers»: Revista de Sociologia *

la seva anàlisi. La desregulació legal de formes de treball anteriorment regulades es relaciona més amb governs netament conservadors que amb les estratègies més liberals, neokeynesianes o corporativistes de Suècia o Austria. Si és més probable que formes explotadores de treball informal es donin a Nova York més que no pas, per exemple, a Amsterdam, Ilavors aquesta qüestió ha de ser considerada. Ara bé, una anàlisi comparativa sofisticada (Pickvance, 1986) només és possible quan hi ha un acord comú sobre què és el que s'ha d'estudiar.

\section{¿EXISTEIX UNA AUTENTICA «ECONOMIA INFORMAL» EN UNA SOCIETAT DE SOCIALISME D'ESTAT?}

Tot i que és raonable ser molt escèptic davant les afrmacions que consideren que hi ha més d'una economia a Europa Occidental, la qüestió esdevé menys evident en les societats de socialisme d'Estat, l'economia de les quals està centralitzadament planificada $i$ on es pot fer una distinció real entre aquest sector i el sector del metcat privat. Els editors d'una collecció d'articles que examinen aquest fenomen conclouen que «la segona economia crea una esfera econòmica separada i completament diferent del sector de l'Estat en principis operacionals. En aquest aspecte l'economia de l'actual sistema socialista és dual» (Galasi i Sziracki, 1985: 20). Més endavant elaboren aquesta distinció argumentant que la primera economia és dirigida per l'Estat amb una dependència pressupostària d'aquest. La segona economia, al contrari, pot ser regulada per l'Estat, però les unitats utilitzen els seus mitjans de producció propis i elles mateixes poden decidir quan i durant quant de temps aquests mitjans operaran. Les dues economies tenen diferents normes d'operativitat $i \mathrm{~h} i \mathrm{i}$ ha una espècie de competència entre elles. L'Estat preferitia mantenir la segona economia en un paper secundari, però, com veurem, no sempre és capaç d'aconseguir-ho, i ambdues economies intenten evitar les normes fetes per mantenit separades les seves activitats.

Un ptoblema crucial que se li planteja a l'Estat és que la mateixa quantitat de treball produeix més ingressos dirigits al consum en la segona economia que no pas en la primera. Es calcula que gairebé la quarta part del temps total utilitzat en la primera economia es dedica a la segona $\mathrm{i}$ aproximadament una cinquena part del PNB es genera en aquesta esfera.

Un sector en què la segona economia prospera és la construcció. Una enquesta feta a 600 families el 1978 mostrà que un 40 per cent havia ajudat a construir les cases d'altres persones, i d'aquest, més d'una quarta part 
havia ajudat a construir dues o més cases. En els serveis industrials (la reparació i manteniment de vehicles i electrodomèstics), el valor del rendiment brut de la segona economia és similar al de la xarxa de serveis de l'Estat. Com ha assenyalat Stark, «com a treballadors i com a consumidors, els hongaresos viuen en una economia dual» (Stark, 1988).

No obstant això, és especialment interessant veure la manera com s'en-. treteixeixen les dues economies en categories diferents d'empleats en la primera economia. Com a Occident, els treballadors clau estan en una. situació privilegiada. De nou el concepte claus és la flexibilitat: els treba. lladors clau són aquelis que poden mantenir una producció contínua a través. d'estratègies d'improvisació, és a dir, solucions al boc per a l'escassesa de materials o recanvis i el manteniment de la planta. S'adquireix un coneixement espećfic en l'empresa, com la possibilitat d'aconseguir recanvis a pattir dels seus contactes personals amb d'altres tallers i tenir eines especials que els pertanyen personalment, la qual cosa facilita que es faci el trebalk de manera tàpida i més fàcil. Aquest coneixement especiffic possibilita als treballadors clau ascendit en la jerarquia interna de l'emptesa $i$ guanyar plus. amb l'ajuda de les seves pròpies eines. Zelosos de la posició privilegiada que tenen, aquests treballadors d'élite practiquen estratègies de selectivitat que dificulten als altres treballadors compartir aquests privilegis. A aquests: treballadors els va tan bé en la primera economia, que tenen pocs incentius per treballar en la segona.

Per sota dels treballadors d'élite hi ha els de nivell mitjà que veuen el seu ascens bloquejat. La seva millor estratègia és controlar la telació sou. esforç per a aconseguir un nivell salarial estable: amb un esforç moderat. Atès que la mateixa quantitat de treball proporciona un major ingrés en la segona economia, aquests treballadors tenen més incentius per a utilitzar el seu treball en la primera economia com una classe de descans i dedicar esforços considerables a desenvolupar la seva posició en el sector privat. Això implica que se superin uns problemes substanciais que inclouen la manca de capital, transport, materials i informació de mercat. Les condicions en la segona economia són necessàtiament molt inestables $i$ és inevitable que es produeixin fluctuacions $i$ rotacions.

Per sota dels treballadors de nivell mitjà hi ha les dones, els joves que tenen la seva primera feina $i$ els immigrants recentment arribats de les àrees: rurals, que ni tenen coneixements específics d'empresa ni contactes amb la segona economia. Aquestes categories estan doblement penalitzades i necessiten ingressos múltiples d'altres membres de la família per a sobreviure satisfactòriament.

Una quarta categoria de treballadors inclou aquells específicament qualificats que a pesar de ser necessaris per a les empreses tenen poques ofertes 
de treball. La conseqüiència és que aquests llocs de treball queden fora de la principal estructura organitzacional de l'empresa i les oportunitats d'ascens són limitades. Per tant, aquests trebailadors estan virtualment obligats a canviar d'empresa per promocionar-se i millorar els seus sous. S'assem. blen a aquells oficials de l'Edat Mitjana que gradualment acumulaven coneixement $i$ experiència mentre viatjaven. Les empreses determinades a mantenir aquests treballadors qualificats i potencialment mòbils seran més flexibles i tolerants envers ells. Els poden donar més temps lliure, pagar-los tatifes d'hores extres i permetre'ls utilitzar les màquines i els camions de l'emptesa perquè puguin guanyar-se un sobresou fent reparacions i treballs de manteniment en l'economia privada.

L'estratègia de canviar d'empresa com una forma de millotar el sou també la practiquen els treballadors sense qualificació específica, però que assoleixen un increment salarial a costa de la seva relació sou-esforç. Ja que a Hongria no hi ha activitat sindical organitzada que asseguri cap classe de paritat entre empreses i treballadors, la inevitable negociació lliure, donada l'escassesa de força de treball, fa que s'exigeixi molt als treballadors i aquests responen canviant de feina en un intent de guanyar més.

Una categoria final, els anomenats treballadors marginals, fan feines temporals, per exempie, en fábriques de sucre, de conserves $i$ en la construcció. Comprensiblement aquestes persones no es comprometen amb l'ocupació estatal $i$ es queden a casa per treballar en les seves parcelles privades. Aquests treballadors, principalment dones, s'acostumen al criteri alternatiu de treballar parcialment en ei mercat de treball estatal $\mathbf{i}$ també en la seva esfera privada de «petita producció de mercaderies». Aquesta norma, molt usual en ''Anglaterra del xvirn (Berg, 1988; Malcolmson, 1988), també la trobem avui en dia a Itàlia i a Espanya però sense l'aguda distincí entre el sector estatal i el privat.

A partir de 1982 hi hagué una ràpida expansió de societats d'empleats d'empreses estatals (VGMKs) que, en efecte, feien feines subcontractades per les empreses que els llogaven. L'empresa oferia una tarifa pel treball total encomanat i la suma de diners neta es distribuia entre els treballadors implicats. Aquestes VGMKs es convertiren en un element molt dinàmic de l'economia hongaresa. Es triplicaten el 1983 , passant de 2.775 a 9.192 , i ja existien en el 56 per cent de les empreses industrials i en el 67 per cent de les empreses de la construcció. El 1986, aproximadament un de cada deu treballadors manuals pertanyia a aquests grups molt especialitzats i qualificats: el desembre de 1986 hi havia 21.490 societats amb un total de 267.000 membres (Stark, 1988: nota 13). Aquestes VGMKs illustren clarament la interpenetració dels principis de planificació estatal i racionalitat de mercat a Hongria. Donada l'escassesa de força de treball ja mencionada i la necessària te- 
gulació salarial de l'Estat s'entén fàcilment perquè les VGMKs s'han estès tan ràpidament. Les quantitats pagades a les VGMKs compten com a «costos» en comptes de com a sous i per tant burlen legalment la seva regulació. En la pràctica els membres de les VGMKs cobren com a mínim dues vegades més del que guanyarien en treballs realitzats dins l'horati normal i alguns cobren quatre cops més. Alguns fins $i$ tot poden guanyar més de la societat que no pas del seu treball formal.

La idea interessà tant els membres de la direcció com els treballadors. Inicialment va ser innecessari portar força de treball externa, que era fins $\mathrm{i}$ tot més cara que la de les societats internes, $\mathrm{i}$ els treballadors qualificats que eren socis de les VGMKs es comprometeren més amb les seves empreses, mentre els seus incentius per a buscar sous millors en altres llocs baixaven. Aquest últim punt interessà la direcció central de l'Estat, ja que les VGMKs eren vistes com una alternativa acceptable a la liberalització $i$ la creixent desigualtat generada per la segona economia. També interessaren els treballadors, com explica Stark: «Si el mecànic de rentadores d'una empresa estatal aconseguia clients i recanvis del seu treball formal per a les "tasques privades" del seu temps lliure, i si el pagès cultivava intensivament la seva pròpia hectàrea de terra, ccom utilitzaria l'enginy especialitzat en la segona economia el treballador de fundició o l'operari de màquines? » La VGM ofereix una oportunitat d'obtenir ingressos suplementaris en el temps lliure. Com explica un jove delineant industrial:

«La VGM és un sistema més civilitzat que la segona economia. Pots guanyar més diners segons l'habilitat que tinguis $\mathrm{i}$ no en un nivell més baix. Si fas el treball al mateix nivell aquests cèntims extres semblen menys humiliants. Diguem que si necessito diners no hrig de netejar els vidres de la veina o descarregar camions, puc fer el treball que m’agrada i que sé fer. No thi ha gaires possibilitats de fer treball de disseny per a empreses de l'economia negra. En canvi en la VGM continuo fent la meva feina normal, la qual cosa pot desenvolupat-me professionalment al mateix temps."

De la mateixa manera un operari gran va dir:

«No puc cultivar vegetals en una banyera. Els que viuen al camp tenen parcelles familiars de les quals poden treure diners, però a la ciutat no en tenim. En canvi a la VGM em puc quedar al mateix lloc, utilitzar els meus coneixements i treballar amb els meus companys.»

O tal com m'explicà un membre del Comitè Central en una entrevista, «Les VGMKs són les patcelles familiats de la indústria» (Stark, 1988). Els 
planificadors estatals tenien el punt de vista, relativament utòpic, que aquestes societats imprimirien un nou esperit empresarial a les empreses que ajudaria a resoldre els colls d'ampolla en la producció. No bi ha dubte que feren evident la teserva de força de treball de les grans empreses que estava amagada. Com ho resumí Stark, «mentre els treballadors de les economies capitalistes es diferencien pel grau de protecció davant del mercat, els de l'economia socialista es diferencien pel grau de participació en el mercat» (Stark, 1988).

A mitjans dels anys 80 semblava com si les VGMKs tinguessin massa èxit. Les societats començaren a utilitzat el seu propi equip per a produir per al mercat $i$ començaren a treballar independentment de l'empresa que les albergava. Semblaven desenvolupar-se tan ràpidament i eficaçment que els observadors trobaven difícil de seguir els esdeveniments. A principis de 1986 hi havia indicis que les VGMKs treballaven en condicions de mercat més obertes. Quan vaig visitar lia superfície d'una planta metallírgica al nord d'Hongria vaig observar una treballada cartellera visiblement situada fora de l'entrada principal. El grup de sociòlegs hongaresos que m'acompanya" ven se sorprengueren en veure uns 17 anuncis de feines, fons $i$ tot de coll blanc. En aquest cas era una empresa estatal important que s'anunciava per atreure VGMKs de fora cap a la fabrica.

S'ha estimat que el 40 per cent dels treballadots assalariats de la primera economia estatal d'Hongria aconsegueixen ingressos suplementaris de la segona economia, que representen el 25 per cent dels seus sous totals. Tres quartes parts del total de famílies reben algun ingrés de la segona economia, cosa que fa creure que aquests ingressos representen gairebé la meitat del desemborsament dels sous del sector socialista (Gabor, 1985). La situació, segons la conclusió d'un científic social hongarès, és extraordinàriament similat a la de Gran Btetanya actualment:

«Sembla que els grups amb alts ingressos suplementaris aconsegueixen alts beneficis suplementaris, mentre que aquells amb baixos ingressos suplementaris aconsegueixen baixos beneficis suplementaris» (Galasi, 1985: 305).

La polarització sembla créixer a Hongria entre els individus $i$ les families amb diverses feines $i \mathrm{amb}$ múltiples fonts d'ingtessos $i$ aquelles amb restringides fonts d'ingressos. Les noves desigualtats generades a través dels metcats de treball interns són ara molt més evidents per a aquells que es troben exclosos de les oportunitats que brinden les VGMKs. 


\section{FLEXIBILITAT D'OCUPACIO I TREBALL SUBMERGIT}

A Europa occidental el creixement de feines a temps parcial en el sector de serveis $i$ el desenvolupament d'una distinció crucial entre treballadors de centre i perifèria en «empreses flexibles» crea noves divisions en la classe obrera tradicional (OCDE, 1986a). A Europa oriental l'accés diferencial d'oportunitats generadores d'ingrés en la segona economia també crea noves divisions. L'augment de treball submergit i d'autoabastament a Europa occidental no compensa de cap manera el creixement de la desocupació. No és que una forma de treball compensi les oportunitats reduïdes a l'accés a altres formes de treball, sinó que sembla que la situació és d'una polarització social en la qual aquells que es troben en «espirals benignes ascendents» acumulen més formes de treball i fonts d'ingressos en la família, mentre que passa tot el contrati a aquells qui estan atrapats en «espirals malignes descendents» ( $\mathrm{Pahl}, 1988 \mathrm{~b}$ ).

Tant a l'Est com a l'Oest d'Europa és el metcat el que impulsa el canvi i la no-intervenció de l'Estat en la regulació i l'organització de les relacions entre famílies i l'economia formal. Divisions tradicionals entre capital i treball a l'Oest $i$ entre objectius collectius i individuals a l'Est són substituides per divisions basades en les estratègies de trebail d'empreses i treballadors. Com va destacat The Economist el 1983:

«Un creixent nombre d'empreses a Europa estan subcontractant treballadors que anteriorment eren mà d'obra cara i a temps complet i la converteixen en més barata $i$ independent. Els treballadors de coll blanc qualificats poden costar a l'empresa fins a tres vegades el seu sou base en espai d'oficina, salari indirecte $i$ altres despeses generals. Si els acomiaden i signen contractes pels seus serveis, les empreses poden retallar despeses i retenir persones de la seva confiança» (The Economist 4/6/83).

A Hongria, com ja hem vist, l'Estat ha encoratjat un grau important de propietat, gestió i activitat empresarial privada. Això no obstant, és clar que el nou «socialisme empresarial» produeix una tiquesa que crea una categoria de nous rics, conjugada amb un empobriment d'una altra part de la població, és a dir, funcionaris de rang baix i altra gent que no té accés a activitats lucratives no oficials. Treballadors marginals $i$ diversos grups minoritaris formen part d'una significant minoria empobrida.

Aquestes noves divisions no es manifesten en anàlisis sociològiques convencionals que posen una èmfasi desproporcionada de l'estatus ocupacio. nal «oficial» del «treballador principal» d'una família. És clar que l'ocupa- 
ció real d'un treballador pot ser molt menys significant que el lloc que té a l'empresa, la composició de la seva família i altres factors relacionats amb la seva capacitat de dedicar-se a activitats generadores d'ingressos illegals a Occident o en la segona economia de l'Est. Ja estan sorgint unes pràctiques específiques de treball domèstic que exigeixen anàlisis sociològiques molt detallades ( $\mathrm{Pahl}, 1984,1988$ ). Aquestes estratègies impliquen pluriempleats, diferents entorns ocupacionals que donen accés a treball submergit en la segona economia en contextos diferents $i$, finalment, la possessió d'una casa com a centre d'autoabastament. Aquestes estratègies de treball domèstic poden encaixar amb les estratègies de l'empresa quan el treballador principal masculí esdevé un treballador central i la seva dona i els fills solters que ja han deixat d'estudiar es converteixen en treballadors perifèrics de baix sou, $i$ aporten ingressos complementaris per a la família. A les dones casades els pot convenir treballar a temps parcial sobretot en etapes determinades de la seva vida i els joves poden preferir una primera ocupa. ció mal pagada que estar a l'atur. El canvi del sector secundari al de serveis en les economies occidentals ha reforçat la posició de les dones en el mercat de treball (cosa que es reflecteix en la reducció de la diferència salarial entre els sous de dones i els d'homes) (Adams $e t$ al., 1988).

$\mathrm{Si}$ la vella imatge de pautes de desigualtat era d'estrats geològics amb una capa superposada a una altra amb una «falla estructural» entre la classe obrera i la classe mitjana (Parkin, 1972), la nova és més aviat un mosaic, en el qual els mateixos colors reapareixen en llocs diferents. Treballadors del centre $\mathrm{i}$ famílies amb diferents membres amb feina poden trobar-se en diversos contextos depenent de la geografia industrial i urbana del país en qựestió.

En aquest nou context les estadístiques nacionals acostumen a ser positivament errònies perquè suprimeixen variacions reals a favor d'una uniformitat irreal. Estudis detallats basats en mercats locals de treball especifics, que demostren la distribució de totes les formes de treball $\mathrm{i}$ indiquen els processos socials i econòmics subjacents, ens ajudaran a fomentar la nostra comprensió del mateix mosaic, basada en les noves divisions emergents.

Tornant al problema de la investigació comparativa entre països; en comptes de portar a terme encara més projectes individuals d'investigació sobre allò que sembla ser la mateixa temàtica en contextos diferents, el primer pas és clarificar més precisament què és allò que ha de ser l'objecte d'anàlisi, com ja he apuntat. Un suggeriment és concentrar-nos en el «treball submergit», és a dir,

«...l'ocupació (segons actuals indicadors internacionals d'estadístiques d'ocupació), mentre no sigui illegal en ella mateixa, no hagi estat declarada 
a una o diverses autoritats administratives pertinents. Són les que actuen burlant les tegulacions legals, evadint impostos o evitant una teducció de les prestacions de seguretat social» (OCDE, 1986: 67).

Aquesta és una definició pragmàtica i viable però sembla més una definició de comoditat administrativa que d'impacte sociològic. Puix que tota la noció d'una economia o sector informal és gairebé impossible de deffnir d'una manera que abasti sensatament l'àmplia gamma de diversitat empírica, proposo que ja és hora que els sociòlegs deixin de ser paràsits de conceptes d'economistes. La gran part del primer ímpetu per avaluar l'economia informal, com a mínim als Estats Units, procedia dels economistes (per exemple Gutmann, 1977; Feige, 1979). Això no obstant, la investigació detallada de treball informal ha estat portada a terme per sociolegs. Per tant, ara vull plantejar que una anàlisi comparativa la farien avançar més profitosament els sociòlegs concentrant-se en el treball més que no pas en l'economia. D'aquesta manera podem esperar que hi hagi algun avenç genuí en la sociologia comparativa en lloc del simple tractament d'estadístiques.

\section{LA DEFINICIO DE FORMES DE TREBALL A PARTIR DE LES RELACIONS SOCIALS A QUE PERT ANYEN}

Es pot objectar que els intents de definir treball informal es poder frustrat tan fàcilment com els de definir l'economia informal. Proposo un marc analític que es basa parcialment en la definició de la situació d'un actor i parcialment en la comprensió de les relacions socials de les quals forma part una tasca o activitat determinada. Només quan es coneixen les condicions objectives i subjectives es pot determinar el tipus de treball que s'està realitzant. Això no obstant, l'atractiu dẹl meut enfocament consisteix en el fet que ofereix categories que poden comparar-se transnacionalment. La dimensió d'aquestes categories dependrà d'un conjunt complet de variables, però amb un cert grau d'ordres de magnitud es pot establir un marc per a l'anălisi comparativa. Aquestes relacions socials poden ser estructurades per les normes de dominació generades pel sisrema econòmic capitalista, els principis del metcat, tant com per la reciprocitat, i per les jerarquies socials d'edat, sexe, parentiu, veïnatge i grup informal. Un individu pot estar aparentment ocupat en una tasca laboral, però si observem només aquell individu pot oferir-nos poca comprensió de la classe de treball en qüestió o si en realitat es tracta de treball. No tota activitat amb objectius determinats és treball; però si no és treball ni oci, de nou no podetn estar segurs 
fins que no sapiguem més de les relacions socials en què es troba aquesta activitat d'oci. En una festa veiem gent: una persona pot estar compartint una activitat festiva, per tant està ocupada en una forma pura d'oci i asso- ciacio. Per una altra part, una persona que treballi per al British Council o per a l'ambaixada pot estar treballant remuneradament per estar en la recepció. Hi ha una diferència entre treball i oci però no es basa en la naturalesa intrínseca de la tasca o de l'activitat. Per clarificar-ho $i$ introduir més complexitats, un exemple específic es pot investigar més detalladament. ${ }^{7}$

Imaginem una dona planxant. Està davant una post de planxar en la -qual hi ha una brusa o una camisa. ¿Està treballant o s'està divertint i, si està fent el primer, quina classe de treball és? La resposta dependrà de les relacions socials en què es troba la tasca que faci. Investiguem algunes possibilitats.

En primer lloc, la dona podria ser una treballadora assalariada a jornada completa que fabrica peces tèxtils a casa. Si se li paga a tant la peça, podria tenir un incentiu per planxar tantes unitats com pogués. D'una altra banda pot tenir un contracte fix sense cap incentiu per augmentar el nombre de peces que planxa, encara que hi pot haver algun control de qualitat que faci que l'estil o la qualitat del seu treball sigui més important que el seu ritme. L'actitud que prengui en la seva tasca està relacionada probablement amb els termes del contracte que hi ha entre la dona i l'empresari. Pot ser que treballi a temps parcial, o que faci torns que incloguin una part a casa, o bé que faci feines eventuals substituint empleats fixos durant les vacances o fent treball suplementari en èpoques de molta feina. En tots aquests casos, siguin quins siguin els detalls concrets, la dona és, en el fons, una treballadora assalariada: ven la seva capacitat de planxar a qui li dóna feina que és qui li proveeix els materials i possiblement també les eines. Si tingués un accident i perdés la vista o li afectés el braç amb què planxa, la seva capacitat de treball desapareixeria o quedaria reduïda.

$\mathrm{Hi}$ ha un altre truc. Podem descobrir que és bàsicament una treballadora assalariada, cosa que queda determinada per les relacions socials en què es troba la seva tasca però no podem estar segurs que l'empresari sigui honest. És possible que aquesta treballadora no estigui registrada en les Ilistes oficials de l'empresa que s'envien al departament governamental pertinent. Aquesta pot ser una estratègia per evitar, d'un cantó, l'obligació de pagar uns impostos determinats o cotitzacions a la seguretat social i d'altre evitar concedir drets $i$ beneficis als treballadors, per exemple, el nombre de dies festius pagats, els drets de baixa mèdica, el període de maternitat,

7. Aquest exemplc està tret del meu Ilibre, On Work, Blacwell, Oxford i New York, 1988. 
i l'assegurança per si té un accident amb la planxa. Si la persona treballa informalment o illegalment, no afectarà les relacions socials bàsiques del treball assalariat; no obstant això, determinar si està formalment registrada tindrà implicacions fonamentals per a la persona en qüestió. Si la feina es fa informalment no s'ba d'incloure, sens dubte, en cap economia informal separada, però s'ha de descriure com a treball assalariat submergit o negre per distingir-lo de la forma registrada i formalment reconeguda.

Aquesta dona pot estar preparant una peça per a la venda però pot ser propietària de la toba i de la planxa; pot haver tenyit la roba, dissenyat l'estil o adornat la peça a la seva manera. Pot tenir la seva botiga o patada, o pot vendre a partir d'un contracte a comerciants detallistes. Siguin els detalls que siguin, és una treballadora autònoma ocupada en la producció a petita escala de productes. Es responsable del seu propi ritme de treball i de la qualitat del que produeix; pot llogar d'altres, que poden ser o no membres de la seva família. En l'últim cas pot estar immersa en el capitalisme familiar amb els seus propis conjunts distintius de relacions socials. Altra volta, les seves activitats poden estar més o menys reconegudes oficialment $\mathrm{i}$ pot preferir estafar Hisenda a pesar del risc que comporta. Això pot implicar la simple declaració parcial de beneficis o pot, parallelament, pagar a altres persones en efectiu i així no té cap obligació contractual cap a elles.

Fins aquí la dona davant la post de planxar l'hem considerada com un agent generador d'ingressos. No sabem res de la seva edat, estat civil, raça o pre-concepcions $i$ actituds subjectives. Podria ser casada o soltera $i$ en els dos casos pot tenir o no un fill. Suposem que està planxant la peça per a un altre membre de la família amb qui viu. Quina classe de treball serà? De nou necessitem saber més sobre la naturalesa de les relacions socials en què es troba la tasca que fa. Aquesta vegada no ens interessen les relacions socials de producció capitalistes, sinó les familiars o patriarcals, que poden arribar a ser molt complexes. Hi ha una àmplia gamma de possibilitats, la dona pot estar planxant la camisa per al seu amant. La seva ment és plena de pensaments tendres o eròtics i conseqüentment la tasca està molt carregada emocionalment $i$ li ofereix un plaer substancial quan, potser, juga amb fantasies sobre l'altre persona mentre planxa les diverses parts de la peça. Pot haver-li proposat planxar com un acte d'amor, conscient que l'amant està disposat $i$ és capaç de fer-ho ell mateix $i$, certament, ell ho ha fet per a ella en el passat. Llavors la feina és simbòlica: és un treball amb un propòsit, fet per amor, i s'assembla al trebail feixuc de monjos i monges que treballen literalment per amor com un mitjà d'auto-expressió. La diferència entre aquest tipus de treball i l'oci és que en l'últin cas el plaer no residiria solament en l'activitat de planxar. No importaria per a qui s'estigués 
planxant la camisa: l'activitat important seria planxar en si i el plaer s'assemblaria a l'experimentat per aquells que juguen a tennis o pesquen com activitat recreativa.

D'altra banda, la dona pot fer molts anys que sigui casada amb un home que gairebé no pot toletar. Ell vol una camisa neta i ben planxada cada dia. Pot ser que li pegui si no fa allò que ell creu que és el seu deure. La dona fa la seva tasca resignadament dominada per les relacions socials patriarcals. La tasca és una càrrega i no comporta cap plaer: se sent obligada, oprimida i ressentida. Ella és només un exemple de l'opressió de les dones i pot pensar tristament en la injustícia de la situació. Encara que estigui planxant la roba dels seus fills el ressentiment pot ser més o menys el mateix si se sent obligada pel seu rol domèstic i les relacions socials establertes pel poder del seu marit. Si la dona planxa la seva pròpia brusa, de. pendrà molt del context en què la porti. Si l'endemà ha de portar la brusa a l'oficina, llavors és com si estigués treballant per reproduir-se a si mateixa com a treballadora endreçada. Sap que la seva imatge és una part de la forma com demostra la seva eficàcía com a treballadora. Ha internalitzat les expectatives dels directors i collegues, homes o dones, i se sent obligada a vestir-se d'una manera determinada. D'aquesta manera està treballant per al pattó en el seu temps liure, però, evidentment, s'està teproduint tam. bé ella mateixa com a treballadora quan es renta les dents o menja. Això no obstant, faria el mateix encara que no treballés. Per tant, la tasca de planxar la seva brusa està més directament relacionada amb el seu treball i no ho faria si estigués de vacances. Algunes feines exigeixen uniformes especials o roba de treball que l'empresari proveeix i manté. Altres feines no exigeixen res d'això $i$ els treballadors poden vestir com vulguin. Investigant la tasca d'aquesta manera es veu que algunes dones tenen feina extra relacionada amb el treball que fan en el seu temps liture. Els homes solters poden tenir la mateixa càrrega: els casats acostumen a passar la càrrega a les seves esposes.

Pot ser que la dona planxi la brusa de la seva sogra. Una combinació de pressions socials l'han portada a tenir cura d'algú que no és capaç d'ocu. par-se d'ell mateix. Pot estar compromesa amb el que s'ha anomenat eufe. místicament «assistència social». És una treballadora social voluntària i la fan sentir responsable del benestar de la mare del seu marit, cosa que pot impedir-li de tenit un treball remunerat. Aquestes càtregues familiars i de parentiu són molt específiques del gènere. No s'espera que els homes es preocupin de la gent gran de la mateixa manera, i en el cas d'un solter en atur amb un parent que depengui d'ell, els serveis socials proveitien assistència que no s'oferiria a una dona en igual condició. Les relacions socials d'obligació familiar estan netament dividides pel gènere. 
Deixem a part el mercat de treball i la dominació d'edat i sexe de la familia, i considerem les situacions en què la dona planxa per a algú que no és de la seva família. Pot set que faci una mica de feina ocasional com a dona de fer feines $i$ guanyi uns diners suplementaris planxant a casa. Compartiria les relacions socials del lumpen-proletariat ocasional, per molt educat que fos qui li encarregués la feina. Malgrat això, la situació més probable és que planxa sense cobtat tes per a algú que no és de la família. Pot ser membre del grup local de teatre i que el director li hagi encarregat amablement planxar les disfresses dels actors. Pot haver accedit a fer-ho calculant que la seva disponibilitat li donatia prestigi davant del director: aquí ha entrat en una telació basada en la norma de la reciprocitat. La seva assumpció taonable és que en oferir el seu temps i el seu esforç planxant serà remunerada amb un favor compatable en el futur. Pot ser que vulgui un paper en una obra; pot esperar que el director, apreciant molt el que ha fet, es fixarà en altres qualitats més personals; pot desitjar el respecte i el suport dels altres mernbres del grup de teatre. Esperi la recompensa que esperi entendrà la tásca com una inversió: està invertint en reciprocitat i esperarà els interessos que li pertoquen. Si, per altra banda, el director ha donat un cop d'ull per la sala i ha convençut a la dona més propera per fer una tasca avorrida, Ilavors ha patit els efectes de l'opressió patriarcal normativa (suposant que el director no obligui també els homes a quedar-se per tnoure els decorats o pintar el teatre). La dona es pot oferir voluntària per planxar només perquè li encanta l'oportunitat d'ajudar el grup. Pot ser que la tasca sigui un descans agradable de la feina mentalment esgotadora que ella tingui i que li agradi compartir l'ambient escolar del grup de teatre amateur. Pot ser que tan li faci l'agraïment i la gratitud de la recompensa social. L'activitat és un plaer gentsí i pet tant no es classificatia com a treball. Això no obstant, deixaria de ser oci si després d'haver-se ofert diverses vegades per fer la tasca, el grup comencés a suposar que aquella és la seva feina i iniciés a aplicar-li les pressions de dominació collectiva, que l'atraparia en un treball regular.

Això no pretén ser un inventari exhaustiu de totes les pautes possibles de relacions socials en què la tasca de planxar es podria trobar. És només una manera d'investigar les diferents estructures d'obligació que les relacions socials creen, entre les quals es troben el treball assalariat, el domèstic i el social. Evidentment', ens equivocariem si diguéssim que l'enfeinada planxadora no treballa quan no realitza treball assalariat. És important reconèixet, però, que l'orientació donada a la tasca alterava substancialment la forma de treball que l'ocupava. És important distingir entre una persona subordinada, físicament i econòmicament impotent, que visqui amb un marit autoritari, i una altra que convisqui amb un home d'esperit cooperador. 
En el primer cas es podria argumentat que viu en una situació de dominació patriarcal, mentre que en el segon cas si es treu l'estructura dominant de les relacions socials canvia la naturalesa de la tasca. Aquest aspecte és important. No sempre és necessari canviar la naturalesa de la tasca per disminuir la càrrega del treball sinó quue, més significativament, pot ser més eficaç canviar la naturalesa de les relacions socials en què la tasca es troba. Així el grup de teatre pot convertir l'agradable tasca en treball, suposant que ella té l'obligació de fer-lo. De la mateixa manera, la dona que confeccionés les seves pròpies peces de vestir per a vendre-les en la seva parada en podria fer algunes per a donar-les a amics o a parents $\circ$ bé per a intercanviar-les pels seus productes artesanals. En aquest cas els principis d'altruisme i reciprocitat transformarien un producte orientat cap als vaJors d'intercanvi del mercat en alguna cosa produida només pel valor d'ús que té per un amic o parent. No és la naturalesa de la tasca la que determina si els valors d'ús o d'intercanvi es produeixen: és una combinació de les relacions $i$ orientacions socials en què es troba la tasca que defineix la forma de treball. Els significats que els individus aporten quan s'enfronten a una certa tasca són crucials. Durant tot l'exemple hem pensat en una dona fent la tasca. Si en l'exemple ens haguéssim referit a «la persona», molts lectors encara suposarien que era una dona. La tirania del costum i la convenció pot creat treball tant com les relacions de producció.

\section{REGULACIO, DESREGULACIO I DISTRIBUCIO DESIGUAL DE TOTES LES FORMES DE TREBALL}

Ja he suggerit que el terme "economia informal» no és una categoria gaire significativa per a Panàlisi comparativa però la noció de formes de treball pot proveir un marc analític més agut. Això implica un gir d'una perspectiva economicista o getencial que només es preccupa de valotar o controlar l'«economia submergida», sovint per aconseguir un sistema fiscal més eficaç, cap a una perspectiva que sigui més sensible sociològicament. Es pot objectar que concentrar-se en formes de treball no facilita la tasca d'investigació transnacional: el principi de la causalitat plural destaca fins i tot més. La petita producció de mercaderies pot estar augnientant a Ghana, Hongria i Gran Bretanya, potser àdhuc a un ritme similar, però la correlació, evidentment, no implica la causalitat. No obstant això, és cert que hi ha processos globals de causalitat comuns i aquests apuntalen l'anàlisi comparativa.

Primer, i més evidentment, hi ha els darrers esdeveniments en la inter- 
minable batalla entre capital i treball que es produeix ara en l'escenari global. La reestructuració de la indústria en les societats desenvolupades ha portat a una expansió de serveis intensius en treball, basats, sovint, en una força de treball femenina, a temps parcial i subcontractada, a més del foment oficial de petits negocis (Hakim, 1987a; 1987b; Scase i Goffee, 1987; Goffee i Scase, 1987). Les reserves del Govern britànic per tegular les relacions entre empresaris i treballadors signifiquen que el treball que abans estava en l'economia informal ara és perfectament. legal. A diferència de la majoria de països de la Comunitat Europea, el Govern britànic no està disposat a donar suport a una directiva de la CEE sobre els drets mínims dels treballadors a temps parcial (Labour Research Department, 1986). Signiffcativament, és la pressió superior que crea l'expansió extraordinàriament tàpida de les VGMs (les societats empresarials de negocis i treballs) a Hongria. Per reduir els efectes de les incertituds de l'entorn buroctàtic, els directius de les empreses socialistes depenen de la cooperació dels treballadors en moments crucials i claus del procés de producció (Stark, 1986: 495). Això és un exemple excellent de la causalitat plural; formes diferents de treball emergeixen de causes diferents. Com explica Stark:

«Com es diu en el llenguatge de la teoria del mercat dual de treball, mentre que en la economia capitalista els que estan en escales internes de treball del sector "primari" són diferents dels seus homòlegs en el sector "secundari", fins al punt que estan protegits del mercat, el dualisme de l'economia socialista s'estructura segons oportunitats diferencials de participar en el mercat» (Stark, 1986: 497).

Així la fluctuació en la divisió formal/informal està determinada per les formes $\mathrm{i}$ estils canviants de regulació i desregulació en un entorn econòmic incert.

El segon element principal en la nova combinació de formes diferents de treball prové del primer. Els processos que produeixen més treballadors marginals i perifèrics també, paradoxalment, produeixen més treballadors protegits del centre, als quals la seva posició privilegiada permet acumular àdhuc més privilegis realitzant també altres formes de treball. Aquests treballadors privilegiats s'observen millor en el context de les seves unitats familiars. El creixement d'unitats familiars amb més d'un trebaIlador ha estat més pronunciat entre els treballadors manuals qualificats. La meva investigació a l'illa de Sheppey, a Kent, ha demostrat les maneres com aquestes families acumulen més recursos i ingtessos portant a terme diverses formes de treball negre, informal $i$ altres formes de treball comunal i recíproc. Aquells que estan millor situats per a obtenir ingressos del 
seu treball també estan ben situats per a aconseguir ingressos suplementaris informalment en el treball $i$ en feines fora del treball regular ( $P a h l, 1984$; Pahl i Wallace, 1985; Pahl, 1988b). El resultat net és una forma de polarització social amb les families amb diversos membres amb feina a un extrem $i$ les privades del treball a l'altre. Això ha estat curosament documentat a la RFA (Glatzer i Berger, 1985).

Aquesta anàlisi recent a Gran Bretanya i a Alemanya deixa clar que les pautes d'autoabastament $i$ altres formes de treball informal augmenten d'una manera cruelment regressiva la desigualtat estructurada en comptes de reduir-la o compensar-la. ${ }^{8}$ Aixo produeix l'anomenat efecte Matthew -aquells que més tinguin més rebran- (en canvi, aquells que tenen poc, àdhuc allo que tenen se'ls prendrà), i hi ha cada cop més proves que aquest procés s'està produint, cettament, a Gran Bretanya. Això no obstant, seria equivocat suposar que aquesta acumulació de formes de treball és un fenòmen universal. En alguns casos compensació i desregulació poden coincidir. Aquest punt es pot clarificar amb un exemple. A Gran Bretanya si un home està a l'atur i la seva dona té feina, del seu sou es descompten les prestacions per desocupació del seu marit. Per tant, si és una treballadora a temps parcial i de sou baix, la famf́lia no serà perjudicada si deixa el seu treball formal. Tanmateix, si treballa i no declara els seus ingressos (encata que en realitat aquests ingressos no arribin al llindar de la declaració de renda) és probable que sigui sancionada, malgrat que els ingressos suplementaris reduirien les prestacions d'atur del seu marit. Per tant hi ha forts incentius perquè les parelles dels aturats també vagin a l'atur. Això, de totes maneres, no és la norma a altres paìsos europeus com Espanya o Itàlia, on la Seguretat Social (fins al punt que existeix) proveix incentius més que desincentius per al treball informal.

Recents esdeveniments en l'organització del mercat de treball i els canvis en la flexibilitat interna de les empreses creen noves divisions entre treballadors del centre $i$ de la perifèria, entre homes $i$ dones, entre joves $i$ adults $i$ entre les minories racials $i$ grups ètnics $i$ la majoria dominant. La teestructuració industrial i la recessió econòmica de l'última dècada portà que més empreses intentessin mantenir nivells de ptoducció o superar-los

8. Pahl, «Does Jobless Mean Workless», setembre 1987, op. cit., Thomas Klein, Joachim Merz i Klaus Wolff, Poverty, Secondary Occupation and Housebold Production: Empirical Evidence for tbe Federal Republic of Germany, treball núm. 214, Sonderforschungsbereich 3 Mikroanalistische Grundlagen der Gesellschatspolitik. J. W. GoetheUniversitat, Frankfurt, i Universitat Mamnheim, setembre 1986. Resultats similarment sorprenents es trobaren a Nàpols! Vegeu els resultats més interessants en Roberto Serpieri i Antonella Spano, Scelte Informale Nell'Agire di Consumo, p. 110, Universitat de Messina, Sicilia, 1986. 
amb menys treballadors. Això va ajudar a produir un atur més alt en els paisos de l'OCDE. Un cop s'assolí això, les empreses es tornaren cada cop més prudents a l'hora d'incrementar la seva força de treball permanent. Aquesta anomenada «flexibilització» de la força de treball, moltes vegades embolicada en eufemismes com "gestió de recursos humans», té l'objectiu de produir una docilitat neofeudal en els treballadors permanents i mimats del centre, que reben una sèrie de privilegis relacionats amb la sanitat, la seguretat laboral, l'accés a una vivenda, etc. La força de treball perifèrica, al contrari, és tnés probable que tingui contractes temporals i de curta durada i pot ser que no estigui protegida per la legislació laboral. Subcontractar assegura que les despeses fixes de les quals l'empresa és responsable, sigui quina sigui la demanda dels seus productes, es mantinguin al nivell mínim. Tot el risc es passa al subcontractant, que al seu torn està poc disposat a donar feina a una força de treball gran i rígida. Com més va, més feina s'organitza segons una norma típica del comtat de York del segle xvin, on els treballadors individuals treballaven en el seu propi temps, a casa seva, escalfada i mantinguda sense cap ajuda de l'empresa que els proveïa de materials. Aquesta forma de treball, el treball a domicili, està creixent a Espanya, Itàlia i Gran Bretanya, i és probable que continuï expandint-se en altres paisos de l'OCDE mentre hi hagi empresaris que es decantin per l'atractiu de major flexibilitat. Com concloïa un informe de l'Institut Sindical Europeu el 1985:

«És clar que molts països europeus han experimentat un creixement d'ocupació inestable en els últims anys i una proliferació de diferents classes de contractes de treball. A més dels treballadors amb contractes normals, ja existeixen un nombre creixent de treballadors a temps parcial, treballadors eventuals o treballadors amb contracte de temps limitat, treballadors autoocupats $\mathrm{i}$ autònoms de tipus diversos» (p. 103).

El mateix informe ens dóna exemples d'una empresa belga que acomiadà treballadores perquè es negaven a canviar de jornada completa a treball a temps parcial. Aquesta reducció forçosa d'hores de treball només fou dirigida contra les dones. El desig dels directors de reduir els costos de treball a curt termini i fer que la força de treball actuï com un escut protector de l'empresa contra les fluctuacions de la demanda, està reforçant les tendències cap al mercat secundari de treball. Aquests treballadors recentment convertits en perifèrics tenen, de mitjana, sous més baixos per hora que els treballadors de jornada completa. Es probable que treballin menys hores i que al mateix temps rebin un sou més baix per hora.

L'estratègia de moltes empreses de passar a la força de treball els costos 
d'un entorn econòmic incert es defensa a vegades dient que aquests trebaIladors perifèrics són principalment dones que sinó no treballatien. El 1981 les dones representaven el 81 per cent dels treballadors a temps parcial a Bèlgica, un 85 per cent a França i un 94 per cent tant a Gran Bretanya com a Alemanya. Per donar alguna indicació dels ordres de magnitud, hi havia a Gran Bretanya, el 1986, 21 milions de treballadors amb feina. D'aquest total, un 55 per cent eren homes $i$ un 45 per cent eren dones. Però dels 9,4 milions de treballadores, el 42 per cent treballaven a temps parcial. Del total, el 23 per cent, gairebé una quarta part de tots els treballadors llogats, treballaven mitja jornada. Les estadístiques més recents demostren també una nova tendència creixent de treballadors masculins a mitja jornada (DE 1987).

Mentre hi pot haver diferències d'opinió sobre el nivell de sous i pobresa familiar, tothom reconeix que aquells que treballen mitja jornada no poden manterir-se ni mantenir els seus sense ingressos suplementaris. $\mathrm{Cu}$ riosament el sistema de Seguretat Social a Gran Bretanya no permet que els ingressos per treball de mitja jornada es descomptin de les prestacions per desocupació, ja que se suposa que els desocupats han d'estar disposats a treballar a jornada completa. Un assalariat principal a temps parcial pot tenir dret a l'ajuda familiar (Family Income Supplement) sota unes circumstàncies determinades, però aquestes mateixes circumstàncies poden produir més o menys els mateixos ingressos familiars, depenent totalment de la Seguretat Social, sense la càrrega del treball. Les conseqüiències d'aquest factor i d'altres és que la majoría de treballadors perifèrics, ja siguin eventuals, a temps parcial o bé tinguin contracte a curt termini, que cobren sous compostos que no els permeten mantenir-se, viuen en famílies en les quals hi ha un treballador, normalment masculi, a jornada completa. Així que, més que haver-hi nous conflictes i divisions entre els treballadors centrals i els petifètics, cosa que en principi es podria esperar, els treballadors del centre i de la perifèria tenen molt en comú. És probable que comparteixin la mateixa llar i àdhuc el mateix llit. És cert que el creixement de treballadors de sou compost ha causat noves divisions, però és més probable que aquestes es produeixin entre families amb diferents ocupacions $i$ amb alguns assalariats i families amb pocs membres amb feina. Aquesta polarització entre unitats familiars està creixent en les societats d'Europa occidental, on la unitat familiar amb un sol assalariat s'està convertint en una raresa estadistica, limitat a un període molt curt del cicle vital quan les dones decideixen no ser actives econòmicament per treballar com a mares a casa a jornada completa.

Típicament les unitats familiars poden acumular avantatges realitzant altres formes de treball al marge de l'ocupació, com diverses formes d'auto- 
abastament a la llar (Pah1, 1984). Fins i tot treballadors manuals de sou baix poden millorar els ingressos de la familia amb sous compostos $i$, comprant les seves cases a l'Ajuntament en condicions favorables, poden treba. llar per millorar el seu estil de vida i les seves condicions domèstiques: arreglar la llar, posant doble vidre, o fent ampliacions a la cuina. Aprofitant el seu propi treball, les seves pròpies habilitats $i$ eines poden fer estalvis substancials i sovint fer el treball millor. També contribueixen a l'apreciació de capital del seu bé més valuós: la seva casa ( $\mathrm{Pahl}, 1984$ ).

La prova d'aquestes tendències no es limita a Gran Bretanya. Un informe sobre una enquesta representativa de la població adulta d'Alemanya occidental revelava que un 30 per cent de tots els propietaris de vivenda construeixen la seva pròpia casa i el 37 per cent fan gran part del disseny interior. Els autors d'aquest estudi destaquen que és la composició de la unitat familiar la que es correlaciona més amb aquest treball informal al marge de l'ocupació.

«El nivell més baix d'ingressos es pot trobar en unitats familiars d'una sola persona. Les famílies incompletes estan generalment per sota de la mitjana. Al contrari, les famílies completes $i$, especialment, les nombroses,. mostren un alt nivell d'ingressos. Les diferències es mantenen significatives si es controlen el nivell d'ingressos, la classe social i l'edat del cap de la unitat familiar... [aquests factors] tenen influència en la producció de la unitat familiar però no en cada àrea, $i$ generalment no és tan forta com la que té la composició familiar» (Glatzer i Berger, 1988: 517-518).

Mentre que és evident que les dones i els joves tenen una situació desavantatjosa en el mercat de treball, perquè tenen més possibilitat de rebre sous compostos, això no implica que com a membres individuals de la unitat familiat tinguin desavantatge en l'accés al consum. Com ja s'ha explicat abans, això és així perquè els seus sous compostos s'ajunten amb l'ingrés fa-. miliar collectiu. A més els que treballen mitja jornada o en feines temporals $i$ eventuals pot ser que tinguin el temps $i$ els contactes socials per trobar una segona feina. Els que fan dues feines poden incrementar encara més l'ingrés familiar collectiu. És clar que hi pot haver una proporció de treba" lladors principals que es mantenen ells i la seva familia gràcies a diferents feines a hores, de manera que dos o tres sous compostos s'agreguen per fer un ingrés suficient. Actors, músics i artistes es veuen obligats a obrar així per treure's uns ingressos suficients quan de la seva feina preferida no en troben prou. La tendència a acumular més recursos per part d'aquelles famílies que obtenen les seves rendes pel treball s'està documentant a bastants països, especialment en aquells en els quals la diferència entre la força 
de treball del centre i la de la perifèria creix. Aquesta diferència travessa les tradicionals divisions de classe, de manera que, per exemple, un artesà pot estar al centre $\mathrm{i}$ un delineant a la perifèria. $\mathrm{La}$ diferència variarà d'una empresa a una altra. Les aptituds dels treballadors centrals són cada cop més específiques de l'empresa i no són fàcilment transferibles ni introdü̈bles en altres empreses.

S'ha de ressaltar que el creixement dels treballadors amb sous compostos, contractats a temps parcial, és aclaparador en el sector serveis, on hi ha pocs treballadors centrals. Així, a Gran Bretanya, de gairebé sis milions d'empleats de sanitat, educació $i$ altres serveis públics (Divisió 9 de la Classificació Industrial Regular) més d'un terç estaven a temps parcial el 1984. La proporció arriba al 41 per cent en el comerç al detall (DE 1987). Per tant, aquesta polarització entre famílies és probable que reflecteixi variacions urbanes $\mathrm{i}$ regionals en la distribució de la indústria $\mathrm{i}$ en els canvis ocupacionals en les empreses. És probable que les famílies més afectades siguin les de les àrees d'«indústries de xemeneia» en crisi i que tinguin poques oportunitats alternatives en les feines de serveis que proporcionin ingressos a altres membres de la unitat familiar (Harris, 1987). D'aquí ve que aquelles regions amb indústria manufacturera pesada en crisi tinguin alts nivells d'atur i poques oportunitats d'aconseguir i fer treball extra, tant si és submergit com d'autoabastament. Els que ja treballen aconsegueixen la gran part de les oportunitats de trobar més feines; els aturats en tenen menys. Els autoocupats tenen més oportunitats d'arreglar-se l'impost sobre la renda.

Es clar que els governs europeus estan preocupats per les conseqüèn. cies d'aquestes pautes diferents de regulació i desregulació sobre el comportament del mercat de treball, desigualtats d'ingressos i la possibilitat de la formació de bosses de força de treball barata. Programes i polítiques diferents produeixen consequiències socials $\mathrm{i}$ econòmiques diferents. Seria òbviament equivocat posat totes aquestes activitats dins el sac de «'economia informal», amb la implicació que té una entitat autònoma amb una vida pròpia, que l'Estat ha de controlar o manipular d'alguna manera.

\section{CONCLUSIO}

Els sociòlegs haurien, potser, d'estar més disposats a teconèixer els petills que comporta girar-se d'esquena a la foguera mentre miren les tremoloses ombres a la paret. Les formes de la paret són difícils de copsar i can. vien constantment. Si els que estan relacionats amb els estudis comparatius 
de l'economia informal o de formes de treball informal, com jo prefereixo, se centressin més en el poder de les institucions polítiques i econòmiques establertes, les vatiacions de la realitat empirica del treball informal esdevindria més intelligible. O'Higgins concloïa el seu intent heroic d'estudiar la relació entre economies formal i submergida en quatre països ressaltant:

«els resultats emfasitzen la diversitat de les experiències nacionals $i$, en consequèència, la debilitat de les assumpcions generalitzades basades en l'experiència de qualsevol país» (O'Higgins, 1985: 140).

De tota manera, O'Higgins suggerí que hi havia vincles entre l'economia submergida i els canvis estructurals en l'economia formal. Els processos globals d'acumulació de capital i l'Estat a través de les pautes de regulació i desregulació alimenten la foguera. Els sociòlegs i antropòlegs, que han proporcionat tants estudis interessants i detallałs de les formes de treball in. formal i tants informes explicatius ad boc, han de deixar de mirar la paret i mirar la foguera.

La meva posició és que el treball informal i el sector informal són en gran part producte de polítiques $i$ accions dels governs, empresaris $o$, en el cas de les societats socialistes, de controladors buròcrates. Els resultats poden ser molt diversos i els científics socials s'han dedicat generalment més a documentar les consequiències que no pas a centrar-se en les causes. Les estratègies dels empresaris, el creixement de les pautes de regulació i destegulació empresarial i governamental són determinants crucials de les pautes del treball informal en les famílies, sovint mediatitzades per les utilitzacions socials de les noves tecnologies. 


\section{BIBLIOGRAFIA}

Adams, M., Maybury, R, i Smith, W. 1988: Trends in the Distribution of Earnings 1973-1976, Employment Gazette, febter, pp. 75-82.

Barthelemy, Philippe. 1982: Travail au noir et economie souterraine: un état de la recherche, Travail et Emploi, Paris, n. ${ }^{\circ} 12: 25-33$.

Berg, M. 1988: Women's Work, Mechanization and the Early Phases of Industrialization in England. A Pahl (ed.), On Work, capítol 3.

Bromley, R. i Gerry, C. 1979: Casual Work and Poverty in the Third World, Chichester i New York; John Wiley.

Davis, J. 1972: Gifts and the UK Economy, Man 7(3) 408-429.

Ditton, J. 1977: Perks, Pilferage and the Fiddle. Theory and Society, 4, 1.38.

Department of Employment 1987. 1984 Census of Employment and Revised Employment Estimates, Employment Gazette, gener 31-37.

EIU. 1982: Coping With Unemployment: The Effects on the Unemployed Themselves. London: Economist Intelligence Unit.

European Trade Union Institute, 1985: Flexibility and Jobs-Myths and Reslities, Brussels: E'TU1.

Feige, E. L. 1979: How Big is the Irregular Economy? Cballenge, novembre-desembre, 5-13.

Ferman, L. A., Berndt, L. i Selo, E. 1978: Analysis of the Irregular Economy: Cash Flow in the Informal Sector. University of Michigan/Wayne State University.

Foudi, Rachid., Stankiewicz, François i Vaneecloo, Nicolas. 1982: Les chomeurs et l'economie informelle. Pp.11.24 a Travail Noir, Productions Domestiques et Entraide. Lille: Laboratoire d'Analyse des Systèmes et du Travail, University of Lille.

Gabor, I. R. 1985: Second Economy: General Lessons of the Hungarian Experience (In Hungarian) Valosag 2: 19-37. Reimprès de manera modificada en un futur volum per Paul Hare. London: George Allen and Unwin.

Gaertner, Wulf., i Wenig, Alois. 1985: The Economics of the Sbadow Economy. New York: Springer Verlag, Heidelberg.

Galasi, P. i Sziraczki, G. (eds.). 1985: Labour Market and Second Economy in Hungary, Frankfurt i New York: Campus Vetlag. 
De l'ueconomia informal» a "formes de treball»

Gershuny, J. I. 1979: The Informal Economy: Its Role in Industrial Society, Futures 3-15.

Gershuny, J. I. 1983: Social Innovation and the Division of Labour. Oxford: University Press.

Glatzer, W. i Berger, R. 1988: Household Composition, Social Network and Household Production in Germany. Reimprès a $\mathrm{Pahl}$ (ed.), On Work, capítol 23.

Goffee, R. i Scase, R. 1987: Entrepreneursbip in Eturope London: Croom Helm. Gorz, A. 1982: Farewell to the Working Class London: Pluto Press.

Gutman, P. M. 1987: The Subterranean Economy, Financial Analyst's Journal Nov-Dec.

Hakim, C. 1987 (a): Homeworking in Britain, Employment Gazette 95 (2). Reimprès a Pahl (ed.), On Work (1988).

Hakim, C. 1987 (b): Home-Based Work in Britain, Research Paper No. 60, London: Department of Employment.

Hatris, C. C. 1987: Redundancy and Recession, Oxford: Blackwell.

Heinze, Rolf G. i Olk, Thomas. 1982: Development of the Informal Economy: A Strategy for Resolving the Crisis of the Welfate State. Futures (juny): $189 \cdot 204$.

Inchiesta, 1986: Special symposium: Economia Informale, Strategie familiari $e$ Mezzogiorno. Núm. 74 (octubre-desembre).

Kohn, M. L. In Press. Cross-National Research as an Analytic strategy, American Sociological Review.

Labour Research Department, 1986: Part-Time Workers.

Malcolmson, R. W. 1988: Ways of Getting a Living in Eighteenth Century England. Reimprès a Pahl (ed.), On Work, capítol 2.

Mattera, P. 1985: Off the Books, London i Sydney; Pluto Press.

Mingione, Enzo. 1983. «Informalization, Restructuring and the Survival Strate. gies of the Working Class». International Journal of Urban and Regional Researcb 7(3): 311-339.

Mingione, Enzo. 1985: «Social Reptoduction of the Surplus Labour Force: the Case of Southern Italy». Pp. 14.15 a Beyond Employment: Housebold, Gender and Subsistence. Oxford i New York: Basil Blacwell.

Mingione, Enzo. 1988: Work and Informal Activities in Urban Southern Italy. A Pahl (ed.), On Work, capítol 25.

Nowak, S. 1976: Meaning and Measurement in Comparative Studies. A Understanding and Prediction: Essays in the Methodology of Social and Bebavioural Theories, pp. 104-132. Dordtecht, Holland: D. Reidel Pubitshing Co.

OECD. 1986a: Flexibility in the Labour Market: the Current Debate. París: Organization for Economic Cooperation and Development.

OECD. 1986b. Employment Outlook. París: Organization for Economic Cooperation and Development.

O'Higgns, M. 1980: Measuring the Hidden Economy: A Review of Evidence and Metbodologies. London. Outer Circle Policy Unit.

O'Higgins, M. 1985: The Relationship Between the Formal and Hidden Econo- 
mies: An Exploratory Analysis for Four Countries. Pp. 127-143 a Wulf Gaertner i Alois Venig, eds. The Economics of the Sbadow Economy. New York: Springer Verlag, Heidelberg.

Pahl, E. 1984. Divisions of Labour. Oxford and New York: Basil Blackwell.

Pahl, R. E. i Wallace, Claire. 1985: Household Work Strategies in Economic Recession. A. Redclift i Mingione (eds.) capitol 6.

Pahl, R. E. 1987: «Does Jobless Mean Workless? Unemployment and Informal Work». Annals AAPSS 493 (setembre): 36.46.

Pahl, R. E. (ed.). 1988(a): On Work: Historical, Comparative and Theoretical Approaches. Oxford i New York: Basil Blackwell.

Paht, R. E. 1988(b): Some Remarks on Informal Work, Social Polarisation and the Social Structure. International Journal of Urban and Regional Research, juny.

Parker, G. 1988: Who Cares? A Review of Empirical Evidence from Britain. A Pahl (ed.), Ont Work (1988), pp. 496-512.

Parkin, F. 1972: Class Inequality and Political Order, London: Paladin.

Pickvance, G. 1986: Comparative Urban Analysis and Assumptions about Causality. International Journal of Urban and Regional Researcb 10(2): 162-184.

Piore, M. F. i Sabel C. F. 1984: The Second Industrial Divide, New York, Basic.

Portes, A. i Sassen-Koob, S. 1987: Making it Underground: Comparative Material on the Informal Sector in Western Market Economies. American Journal of Sociology, 93(1), 30-61.

Redclift, Nanneke i Mingione, Enzo. 1985: Beyond Employment. Oxford i New York: Basil Blackwell.

Renooy, P. H. 1984: Twilight Economy: A Survey of the Informal Economy in the Netberlands. Amsterdam The University, Faculty of Economic Sciences.

Roberts, B. R. 1987: Labor Markets and Class Organization: Britain, Spain and Mexico. Comunicació presentada a una sessió temàtica de la Reunió Anual de I'Associació Americana de Sociologia feta a Chicago. Mimeo: University of Texas at Austin.

Sabel, C. F. 1982: Work and Politics, Cambridge: University Press.

Scase, R. i Goffee, R. 1987: The Real World of the Small Owner, 2a. edició, London: Croom Helm.

Skolka, J. V. 1976: «Long-Term Effects of Unbalanced Labour Productivity Growth: On the Way to a Self-Service Society». Pp. 280-301 a Private and Enlarged Consumption: Essays in Metbodology and Empirical Analysis, editat per L. Solari i J.-N. du Pasquier, North Holland; Amsterdam.

Sik, E. 1988: Reciprocal Exchange of Labour in Hungary, a Pah1 (ed.), On Work, capítol 24.

Smith, S. 1986: Britain's Sbadow Economy, Oxford: Clarendon Press.

Stark, D. 1986. Rethinking Internal Labour Markets: New Insights from a Comparative Perspective, American Sociological Review (51) 492-504. Reimprès a Pahl (ed.), On Work (1988), capitol 14.

Stark, D. 1988. Towards a Polyphonic Economy: The Diversification of Organisational Forms in Hungary. A Victor Nee i David Stark (eds.) Remaking 
De l'«economia informal» a «formes de treball».

the Economic Institutions of Socialism: China and Eastern Europe. Stanford: Stanford University Press.

Thomas, J. J. 1988: The Politics of the Black Economy, Work, Employment and Society, juny.

Ungerson, C. 1987: Policy is Personal: Sex, Gender and Intormal Care, London: Tavistock. 